\title{
MANIFESTAÇÕES MISÓGINAS NO HUMOR: CRIME OU REFLEXO DA LIBERDADE DE EXPRESSÃO?
}

\author{
MISOGYNIST MANIFESTATION IN HUMOR: CRIME OR REFLECTION OF \\ FREEDOM OF SPEECH?
}

\section{Joana Selis Santos Caldas ${ }^{1}$}

Resumo: O presente trabalho analisou, por meio da revisão bibliográfica, as manifestações misóginas no humor, buscando compreender seu status no ordenamento jurídico brasileiro, ou seja, se é revestido como crime ou ramificação da liberdade de expressão. Para tanto, foi explorada, primeiramente, a liberdade de expressão, observando seu amparo e previsão na legislação brasileira, como também seus limites jurídicos. A partir disso, foi possível identificar os crimes que ferem a honra do indivíduo, averiguando a sua colocação na hierarquia normativa e verificando as antinomias presentes na Constituição Federal. Fato, este, que levou a uma inquirição de jurisprudências que se relacionam com a temática em questão, como, a ADI n. 4451. Dessa forma, verificou-se, na jurisdição brasileira, o papel desempenhado por piadas consideradas misóginas. Tendo como base os aspectos explorados, as antinomias e a divergências nas jurisprudências examinadas, concluiuse que não há uma resposta objetiva para a indagação, o que possibilitou depreender que cada caso deve ser analisado individualmente levando em consideração suas singularidades.

Palavras-chave: Humor; Limites da liberdade de expressão; Misoginia.

Abstract: The present article analyzed, through bibliographic review, the misogynistic manifestations in humor, seeking to understand their status in the Brazilian legal system, that is, if it is covered as a crime or a branch of freedom of expression. To that end, freedom of expression was explored, observing its support and foresight in Brazilian legislation, as well as its legal limits. From this, it was possible to identify the crimes that hurt the individual's honor, investigating their placement in the normative hierarchy and verifying the antinomies present in the Federal Constitution. This fact led to an investigation of jurisprudence that is related to the subject in question, such as ADI n. 4451. Thus, the role played by jokes considered misogynistic was verified in Brazilian jurisdiction. Based on the aspects explored, the antinomies and divergences in the examined jurisprudence, it was concluded that there is no objective answer to the question, which made it possible to infer that each case must be analyzed individually taking into account its singularities.

Key Words: Humor; Limits on freedom of expression; Misogyny.

\footnotetext{
${ }^{1}$ Graduanda do curso de Direito da Universidade do Estado da Bahia (UNEB). E-mail: $<$ joanaselis14@gmail.com>.
} 


\section{INTRODUÇÃO}

A sociedade é constituída, em sua maior parte, por relações de poder, as quais se manifestam de diversas formas, variando de acordo com os membros dessas relações e também com o meio em que eles estão inseridos. Uma das relações - que pode ser considerada presente em grande parte do mundo - é, indubitavelmente, a relação entre pessoas dos gêneros feminino e masculino. Nessa relação há uma ocupação superior hierárquica do gênero masculino em relação ao feminino, constituindo uma relação assimétrica manifestada em diversas ações comportamentais, como, por exemplo, falas e atitudes consideradas misóginas.

Tendo como base os crimes contra a honra presentes no Código Penal (CP) e os direitos garantidos ao cidadão brasileiro na Constituição, há a possibilidade dessas manifestações serem enquadradas como crime. Todavia, tal possibilidade entra em uma linha tênue quando abordada em um contexto específico - as manifestações misóginas no humor, existindo divergentes entendimentos acerca de seu status no ordenamento jurídico brasileiro.

De um lado, há um grupo que se utiliza de vários argumentos para descaracterizar o humor misógino como ofensa, defendendo a intenção, o meio em que ele está sendo dito, o direito à liberdade de expressão. Do mesmo modo, existe outro que busca comprovar o seu status como uma manifestação ilegal.

Diante disso, surge a pergunta que foi utilizada para a realização desta pesquisa - "manifestações misóginas no humor é um crime ou um reflexo da liberdade de expressão?". Tal enfoque para realização desta pesquisa está relacionado, principalmente, com o destaque que a questão está recebendo na atualidade, tendo sido amplamente debatida na mídia e redes sociais, além de sua grande relação com o Direito, uma vez que está ligada em seu cerne com a hierarquia da legislação, sobre qual prevalece em uma questão como essa.

Ademais, trata-se de um tema com um grande significado pessoal, pois, é uma pesquisa realizada por uma mulher, um grupo que é frequentemente alvo de piadas que podem ser consideradas ofensivas. Além do mais, a temática desta pesquisa não tem sido abordada diretamente em textos científicos/acadêmicos, sendo tratados 
somente temas similares ou que se relacionam, retratando este artigo uma abordagem com um viés diferente, levando para a discussão elementos diversos como a sexualidade.

O método de investigação científica adotado no estudo foi o da revisão bibliográfica. Dessa forma, para a sua realização, primeiramente, procura-se coletar um breve referencial teórico e bibliográfico acerca do tema, isto é, buscar artigos que retratam o tema escolhido e/ou temáticas que dialoguem com ele. A busca por esse referencial foi concretizada através de uma pesquisa em banco de artigos utilizando como palavras-chaves termos relacionados com a pesquisa (como, por exemplo, "humor", "liberdade de expressão", "limites da liberdade de expressão"). Foi possível, portanto, ampliar o conhecimento acerca da temática e encontrar meios de aprofundar a pesquisa.

Vale destacar que, em relação a jurisprudência pesquisada, mantive um foco nas decisões do Supremo Tribunal Federal (STF). Essa decisão está relacionada com a hierarquia que esse órgão possui no Poder Judiciário - sendo a mais alta instância desse ramo do poder.

A partir disso, ao longo da pesquisa busco encontrar resposta ao questionamento do humor enquanto crime ou ramificação da liberdade de expressão abordando temáticas como os limites da liberdade de expressão, hierarquia legislativa, ofensa $\mathrm{X}$ engraçado, direito ao trabalho do comediante, direito à honra.

\section{MISÓGINIA NO HUMOR ${ }^{2}$}

O humor é um tema debatido, analisado e pesquisado por diversas áreas acadêmicas, todavia, não há um consenso acerca de sua definição. Uma que pode

\footnotetext{
${ }^{2}$ A misoginia será considerada, no presente artigo, como o ódio, aversão, desprezo, preconceito contra o gênero feminino. Gênero (que difere de sexo, o qual parte de uma determinação biológica, definindo os seres humanos em homens e mulheres) é o fruto de uma construção do indivíduo através da sociedade e da civilização em feminino e masculino. In: VAN DAMME, E. Gender and sexual scripts in popular US teen series: A study on the gendered discourses in One Tree Hill and Gossip. Catalan Journal of Communication \& Cultural Studies. Gante, Bélgica: Intellect Ltd Article, v. 2, n. 1, 2010. p. 71-92.
} 
ser destacada considera que o cômico ou engraçado (conceituados como a faculdade capaz de fazer uma pessoa rir ou diverti-la) é composto pelo o humor e outros elementos, como diversão, absurdo, sarcasmo, ironia, sátira. Nessa concepção, o humor está relacionado a uma atitude sorridente em relação à vida e as imperfeições. Outra definição que também é importante citar define o humor como o termo guardachuva desse campo, substituindo o que era considerado o cômico na conceituação anterior, ou seja, o humor passa a ser o aspecto que é composto pela diversão, o absurdo, sarcasmo ${ }^{3}$.

No Brasil, é evidente que humor está fortemente relacionado com piadas que ridicularizam grupos considerados minorias (como os negros, os nordestinos, os homoafetivos, as mulheres). Vários exemplos que notabilizam essa relação podem ser citados, como os "Trapalhões" - programa televisivo humorístico produzido entre 1977 e 1995, mas que ainda é exibido atualmente - que pode ser considerado racista, homofóbico, sexista, e "Toma Lá Dá Cá" - série televisiva de humor que começou a ser produzida em 2007 e terminou em 2009, sendo ainda exibida - também contém piadas sexistas, homofóbicas, racistas.

Apesar de ter vários exemplos que foram produzidos no passado, piadas que podem ser consideradas ofensivas ainda fazem parte do dia a dia do povo brasileiro. Recentemente, um caso envolvendo piadas que contém essa determinada característica ganhou grande atenção midiática e iniciou uma onda de debates em redes sociais. O humorista Danilo Gentili - conhecido por apresentar o programa "The Noite com Danilo Gentili", no canal SBT (Sistema Brasileiro de Televisão) -, em um vídeo, referiu-se a deputada Maria do Rosário (PT-RS) utilizando o termo "puta". A $5^{\text {a }}$ Vara Federal Criminal do Estado de São Paulo ${ }^{4}$ entendeu que esse conteúdo caracteriza um crime de injúria contra a deputada (tipificado no artigo 140 do CP). Gentili, todavia, argumenta que realizou apenas uma piada - não tendo o dolo de ofender a deputada, não caracterizando, portanto, um ato típico - e a qual é uma ação permitida tendo como base o direito de liberdade de expressão - garantido aos

$3 \mathrm{RUCH}$, W. The Perception of Humor. In: KASZNIAK, A. W. (Org.). Emotions, Qualia, and Consciousness. Düsseldorf: World Scientific Publishing Co. Pet. Ltd., 2001. p. 410-425.

${ }^{4}$ SÃO PAULO. 5 ${ }^{\underline{a}}$ Vara Criminal do Tribunal Federal da 3르 Região. Ação Penal Privada. São Paulo, 10 abr. 2019. 
brasileiros pela Constituição Federal de 1988 (CF $)^{5}$. Essa situação ocasionou uma dicotomia nas redes sociais entre aqueles que apoiavam a decisão judicial e aqueles que defendiam Gentili e consideravam que por conta do direito à liberdade de expressão tal ação não poderia ser penalizada.

Logo, é possível perceber que em situações como essa surge um questionamento fortemente entrelaçado com o direito: piada - enquanto gênero textual humorístico - quando é considerada uma ofensa à uma pessoa ou a um grupo alvo, é um crime, tipificado pelo $\mathrm{CP}$, ou é uma ação que está englobada no direito à liberdade de expressão (o qual é garantido ao cidadão brasileiro) no ordenamento jurídico?

\section{O INDIVÍDUO É REALMENTE LIVRE PARA SE EXPRESSAR?}

Liberdade pode ser definida como a "[...] faculdade de cada um se decidir ou agir segundo a própria determinação"6. Existem, contudo, diversas conceituações do vocábulo, sendo ele alvo de análise por diversos filósofos ao longo da história, os quais fornecem divergentes definições da palavra. Aristóteles, por exemplo, relacionava a liberdade com a ideia de escolher de um modo voluntário e racional ${ }^{7}$, já Immanuel Kant - pensador europeu conhecido como "maior filósofo da Modernidade" - considera que liberdade seria seguir as leis ${ }^{89}$.

Jean-Paul Sartre, todavia, discorre sobre a liberdade indo além do livre arbítrio, considerando que a liberdade é a única determinação do ser humano (ele é livre para ser o que deseja), mas ela está conectada com responsabilidades acerca das

\footnotetext{
${ }^{5}$ LIMITES Ultrapassados: Danilo Gentili é condenado à prisão por injúria contra deputada Maria do Rosário. Consultor Jurídico, 11 abr. 2019. Disponível em: https://www.conjur.com.br/2019-abr11/danilo-gentili-condenado-prisao-injuria-maria-rosario. Acesso em: 30 abr. 2019.

${ }^{6}$ LIBERDADE. In: Dicionário Aurélio da Língua Portuguesa. Brasil: Positivo, 2019.

${ }^{7}$ MENDONÇA, B. M. Liberdade: dos Pensadores ao Direito Fundamental. Direito UNIFACS - Debate Virtual, Salvador, v. 227, maio 2019. Disponível em: https://www.revistas.unifacs.br/index.php/redu/article/view/513. Acesso em: 12 dez. 2019.

${ }^{8}$ Essa definição se entrelaça com uma das definições presentes no dicionário Aurélio: "faculdade de praticar tudo quanto não é proibido por lei".

9 AMORIM, R. G. Immanuel Kant: "O maior filósofo dos tempos modernos". In: Coleção Estudo Filosofia/ Sociologia. Belo Horizonte: Bernoulli Sistemas de Ensino, 2017, v. 2, p. 49-62.
} 
decisões tomadas pelas pessoas, ademais ele também afirma que em relação a liberdade não há um meio-termo, ou ela é absoluta ou não existe ${ }^{10}$.

Acerca da liberdade, em seu sentido amplo, enquanto uma característica indissociável da condição humana, sustentam Caio Eduardo Costa Cazelatto e Valéria Silva Galdino Cardin que se trata de

[...] um dos bens e, ao mesmo tempo, uma das qualidades mais imanentes da condição humana. É ela que permite ao indivíduo vivenciar ou transmitir a sua própria identidade, os seus pensamentos, o seu ir e vir, além de viabilizar a atividade de inúmeros outros atributos ou direitos. ${ }^{11}$

Apesar de não existir um consenso acerca do significado de liberdade, há uma certeza em relação a ela no Brasil: é um direito garantido ao cidadão brasileiro e ao estrangeiro que aqui reside pela $\mathrm{CF}$ em seu quinto artigo e regulado em alguns de seus 78 incisos e parágrafos, sendo incluído nesse rol de direitos uma ramificação da liberdade, a liberdade de expressão.

Artigo $5^{\circ}$ Todos são iguais perante a lei, sem distinção de qualquer natureza, garantindo-se aos brasileiros e aos estrangeiros residentes no País a inviolabilidade do direito à vida, à liberdade, à igualdade, à segurança e à propriedade $[. . .]^{12}$

O termo "expressão" está, evidentemente, relacionado ao verbo "expressar", o qual se refere ao ato de expor uma ideia, um pensamento. A manifestação da liberdade de expressão, portanto, consiste na utilização desse direito - o qual é garantido pela Carta Magna - para transmitir convicções, opiniões, críticas seja através de fala, de filmes, do teatro. O humorista, ao realizar uma piada que possa ser considerada misógina, está se expressando.

Sendo assim, é necessário - para se obter um entendimento claro e que abranja as camadas do questionamento que o presente artigo foca - uma análise do

\footnotetext{
${ }^{10}$ AMORIM, R. G. Os principais pensadores do século XX. In: Coleção Estudo Filosofia/ Sociologia. Belo Horizonte: Bernoulli Sistemas de Ensino, 2017, v. 2, p. 95-118.

${ }^{11}$ CAZELATTO, Caio Eduardo Costa; CARDIN, Valéria Silva Galdino. Minorias Sexuais e Discurso de Ódio. Rio de Janeiro: Lumen Juris, 2018, p. 75.

12 BRASIL. Constituição da República Federativa do Brasil. Brasília, DF: Senado, 1988.
} 
modo em que a liberdade de expressão é vista pelo ordenamento jurídico brasileiro, uma vez que, a forma em que ela é alisada varia dependo, por exemplo, do contexto cultural, como as divergentes conceituações expostas acima demonstram.

\subsection{LIBERDADE DE EXPRESSÃO NO ORDENAMENTO JURÍDICO}

$\mathrm{Na}$ CF, é abordada cristalinamente a liberdade de expressão, o artigo 5으. IV assegura a liberdade de manifestação do pensamento e veda o anonimato. Além disso, o mesmo artigo, mas no inciso IX, é garantida a liberdade de expressão de atividade intelectual, artística, científica e de comunicação.

A liberdade de expressão caracteriza um direito que compõe o rol dos direitos fundamentais, isto é, os "[...] direitos público-subjetivos de pessoas (físicas ou jurídicas), contidos em dispositivos constitucionais, [...] tendo como finalidade limitar o exercício do poder estatal em face da liberdade individual” ${ }^{13}$. Os direitos individuais e coletivos, de acordo com o artigo 60 da CF, garantidos pela Constituição - o que inclui, portanto, os direitos fundamentais - são considerados cláusulas pétreas, dessa forma, não podem ser alterados através de uma Emenda Constitucional. ${ }^{14}$

Vale destacar o contexto histórico da criação dessa carta Magna, o que influencia diretamente em seu conteúdo. Em 1964, ocorreu - no Brasil - um golpe militar, o que resultou em uma ditadura marcada pela imposição de uma série de normas que restringiam a liberdade de expressão da população brasileira, transformando o país em uma localidade marcada pela censura. Esse regime autoritário teve fim em 1985, sendo a CF hoje vigente um marco da redemocratização do país. Logo, foi de extrema importância a clara garantia desse direito em nossa Constituição. ${ }^{15}$

\footnotetext{
${ }^{13}$ DIMOULIS, D.; MARTINS, L. Teoria Geral dos Direitos Fundamentais. 5. ed. São Paulo: Atlas, 2014.

14 Ibid., p. 37.

15 "Um dos pontos altos da Constituição é o artigo $5^{\circ}$ que garante as amplas liberdades, principalmente para um país como o nosso, marcado pelo autoritarismo [...]." In: VILLA, M. A. História das Constituições Brasileiras. São Paulo: Textos Editores LTDA., 2011.
} 
Pode-se definir a liberdade de expressão, conforme elucidam Caio Eduardo Costa Cazelatto e Valéria Silva Galdino Cardin, como:

[...] o direito de transmitir, independentemente da formulação de convicções, juízos e conceitos do Estado ou de terceiros, a linguagem em suas mais diversas formas, como por meio da música, da pintura, do teatro, da fotografia, do filme, do livro, dos gestos ou mesmo pelo silêncio. ${ }^{16}$

Apesar disso, o direito à liberdade de expressão não é ilimitado ${ }^{17}$, isso porque "[...] essas restrições são mecanismos de organização social responsáveis por assegurarem a efetividade dos demais direitos que possam ser lesados pela prática inconsequente da liberdade de expressão". ${ }^{18}$

Logo, apesar de constituir um direito garantido a todos os cidadãos brasileiros, a liberdade de expressão não pode ser considerada um direito tão amplo, ilimitado. Dessa forma, para compreender o status das manifestações misóginas do humor no ordenamento jurídico brasileiro é necessário analisar quais seriam essas limitações.

\section{2 "A MINHA LIBERDADE COMEÇA QUANDO TERMINA A DO} OUTRO”

O CP estabelece - no Capítulo V do Título I da Parte Especial - os crimes contra a honra ${ }^{19}$, entre eles está a injúria (artigo 140), caracterizando que ao ofender a dignidade (referindo aos atributos morais do indivíduo) e o decoro (referindo a

${ }^{16}$ CAZELATTO, Caio Eduardo Costa; CARDIN, Valéria Silva Galdino. Minorias Sexuais e Discurso de Ódio. Rio de Janeiro: Lumen Juris, 2018, p. 80.

17 "A liberdade de expressão, a despeito de possuir uma preferred position nas democracia constitucionais contemporâneas, pode sofrer limitações, desde que razoáveis, proporcionais e visem prestigiar outros direitos e garantias do mesmo status jusfundamental." In: BRASIL. Agravo Regimental em Mandado de Segurança 34.493 Bahia, de 06 de Maio de 2019. Brasília, 3 maio 2019. Disponível em: http://portal.stf.jus.br/processos/downloadPeca.asp?id=15340142676\&ext=.pdf. Acesso em: 30 out. 2019.

18 Ibid., p. 86.

${ }^{19}$ A honra possui duas dimensões: uma subjetiva ou interna e uma objetiva ou externa. A primeira dimensão está ligada com a valoração que cada pessoa tem de si mesma, o que interfere na expectativa que ela tem acerca de como as pessoas da sociedade devem agir em relação a ela. Já a outra dimensão é acerca da opinião das outras pessoas sobre nosso comportamento, tendo como base os valores culturais estabelecidos na sociedade, que determina a reputação do indivíduo na sociedade em que vive. In: MOREIRA, A. Racismo Recreativo. São Paulo: Polén, 2019. 
aspectos morais e/ou intelectuais) de pessoa alheia estaria realizando uma ação que pode resultar em detenção de um a seis meses ou multa ${ }^{20}$.

Tal pena não seria aplicada em duas situações, de acordo com o referido artigo, quando o ofendido provocou diretamente esse ato criminoso e se correr retorsão imediata que seja outra injúria. Além disso, o artigo $7^{0}$ da lei 11.340 de 7 de agosto de 2006 - conhecida como Lei Maria da Penha - exemplifica como umas das formas de violência doméstica e familiar contra a mulher a violência moral, estabelecida como uma conduta que se configure calúnia, difamação ou injúria.

Uma das características da injúria é que pode ser realizada por qualquer pessoa, exceto aqueles que dispõem de imunidade (como, por exemplo, Deputados, Vereadores, Senadores, advogados) ${ }^{21}$. Portanto, levando em consideração tais elementos acima apontados, seria possível considerar que o comediante ao realizar uma piada considerada misógina estaria cometendo uma injúria.

Todavia, é importante salientar que a injúria difere do racismo, enquanto o primeiro é em relação a uma pessoa em específico o segundo é acerca de uma etnia em geral, como, por exemplo, a parcela da população brasileira que se identifica como negra ${ }^{22}$. Outrossim, o crime de injúria possui como uma de suas características nucleares o fato de ter que existir o dolo, não sendo tipificado pela legislação brasileira esse crime caso não tenha havido a intenção de ferir a honra de terceiro(s) ${ }^{23}$.

Isso faz surgir um questionamento, ao realizar uma piada considerada ofensiva estaria o humorista realizando uma injúria? ${ }^{24}$ Apesar de ferir a honra de outrem, é possível considerar que não havia a intenção de machucar alguém, o comediante

\footnotetext{
20 BRASIL. Decreto-Lei 2.848, de 07 de dezembro de 1940. Código Penal. Diário Oficial União, Rio de Janeiro, 31 dez 2019.

${ }^{21}$ LENZA, P. (Org.). Direito Penal Esquematizado: Parte Especial. 8. ed. São Paulo: Saraiva, 2018.

22 Adilson Moreira apresenta uma crítica a esse posicionamento da doutrina, jurisprudência e da legislação brasileira. No ponto de vista do autor, não existe essa divergência entre a natureza do racismo e da injúria racial, pois ao estar realizando uma ofensa a um indivíduo negro especificamente, também está, consequentemente, realizando uma ofensa à comunidade negra em geral. $\mathrm{O}$ autor entende que a honra possui uma dimensão coletiva, porque a ofensa em relação a uma pessoa não resume apenas a ideia de uma pessoa em relação a ele, mas sim ao modo como enxerga o grupo. Ademais, Moreira considera que esse posicionamento constitui uma tentativa para pessoas que realizam atos racistas receberem penas mais brandas (MOREIRA, op cit.).

${ }^{23}$ LENZA, P. (Org.), op. cit., p. 282.

24 O CP - artigo 140, $3^{\circ}$ - aborda a existência de uma injúria qualificada, que consiste na utilização de aspectos em relação a raça, cor, etnia, religião, origem ou condição da pessoa idosa ou portara de deficiência, e que tem uma pena maior que a injúria "tradicional". Como pode observar não há a referência a gênero e/ou sexo nesse tipo penal.
} 
visava apenas fazer seu público rir, realizar o seu trabalho, não havendo, portanto, dolo na situação e não se caracterizando como a ação tipificada no CP.

Contudo, uma possibilidade que não podemos esquecer é que os humoristas podem utilizar essas piadas com o intuito de camuflar o preconceito. Nelson Hungria, ao listar exemplos de injúrias, cita a ironia, isto é, uma pessoa utilizar da ironia para ofender outro indivíduo ${ }^{25}$. A ironia - como foi citado anteriormente - é um dos elementos que compõe o humor.

Ademais, Adilson Moreira - em sua obra "Racismo Recreativo"26 - discorre acerca da existência do racismo recreativo, isto é, a utilização de piadas para disfarçar o racismo. Na visão desse autor, o racismo é um dos elementos utilizado por indivíduos brancos para a manutenção do seu poder, além de possuir - de acordo com Moreira - como uma de suas principais características o fato de ser dinâmico, ou seja, vai sendo alterado ao longo dos anos para que continue a ser praticado e, consequentemente, essa manutenção ocorra. Atualmente, vivemos em um contexto em que demonstrações de intolerância são moralmente e judicialmente condenadas, sendo assim, o racismo recreativo é utilizado para que os ideais racistas perpetuem na sociedade sem que ocorra o racismo em sua forma tradicional.

O racismo recreativo possui como principal diferencial em relação ao racismo em sua forma tradicional o seu status no ordenamento jurídico. A pessoa que realiza a piada racista argumenta que a mesma possui um caráter recreativo, não constituindo crime uma simples piada; argumenta ainda possuir amigos negros e que no Brasil, país marcado pela miscigenação, não há racismo. Moreira afirma que esse é o racismo sem racistas. Criticando alguns desses argumentos, ressalta que para ser considerada engraçada, uma piada racista tem que estar inserida em um contexto racista, ou seja, essa piada apenas será engraçada se compreendermos que, apesar de possuir um caráter negativo, esses são os estereótipos relacionados a esse grupo de pessoas.

Moreira $^{27}$ argumenta que o status que o racismo recreativo possui no ordenamento jurídico brasileiro é apenas uma das diversas ferramentas do branco

\footnotetext{
${ }^{25}$ HUNGRIA, N. Comentários ao Código Penal. In: LENZA, P. (Org.). Direito Penal Esquematizado: Parte Especial. 8. ed. São Paulo: Saraiva, 2018.

${ }^{26}$ MOREIRA, op. cit.

$27 \mathrm{lbid}$.
} 
utilizadas para perpetuar o seu poder. Ele corrobora seu ponto de vista analisando uma série de decisões judicias, as quais acredita serem evidentes exemplos de racismo no país, mas que não foram assim consideradas pelo judiciário.

Além disso, Moreira apresenta um lado importante acerca das implicações que o racismo recreativo possui aos indivíduos negros. O racismo recreativo é utilizado para a perpetuação do ideal branco acerca do negro, que tenta demonstrar o negro como um ser promíscuo, não inteligente, semelhante a um animal irracional. Isso afeta psicologicamente os negros e possui consequências materiais, uma vez que contribui para que eles não consigam conquistar uma posição de poder, pois a ideia que é passada acerca deles é de que não possuem características para alcançar uma posição hierarquicamente superior, o que faz com que o entretenimento cultural, as leis e as decisões judiciais ainda sejam determinadas - em sua maioria - por pessoas que não fazem parte dessa parcela da sociedade..$^{28}$

É possível, então, analogicamente, falarmos da existência de uma misoginia recreativa. Se realizarmos uma analogia entre o racismo e misoginia, apesar de constatarmos divergências, também é possível enxergar diversas semelhanças. Piadas misóginas podem sim serem utilizadas para a perpetuação do poder nas mãos de pessoas do gênero masculino, sendo - constantemente - utilizadas para perpetuar a ideia de um indivíduos subordinado ao homem, em uma posição inferior na sociedade, o que afeta as ideias que pessoas desse gênero tem sobre si e o local delas em nossa sociedade. Estariam então, esses humoristas, se aproveitando de uma "brecha" do sistema legal brasileiro?

Além disso, a possibilidade dos humoristas serem capaz de legalmente realizarem piadas que ofendem pessoas do gênero feminino criam um precedente para a população, que passa a entender que podem realizar o mesmo, mas com a possibilidade de não restringir a misoginia para o humor, o que - tecnicamente - a tornaria um crime ${ }^{29}$. Dessa forma, é possível considerar que isso corroboraria a normalização da misoginia no cotidiano do brasileiro.

${ }^{28}$ MOREIRA, op. cit.

${ }^{29}$ A realização piadas misóginas para uma audiência (o que geralmente é a situação em que os humoristas realizam as suas piadas que podem ser consideradas ofensivas) se enquadrada como injúrias teriam sua pena aumentada em virtude da situação em que ocorre, diante de um grupo de 
Ademais, também seria possível argumentar que em situações em que há piadas ofensivas seria possível inserir a responsabilidade civil (descrito no artigo 186 do Código Civil), isto é, a obrigação que o indivíduo possui de reparar o dano que causa a terceiro. É inegável que a realização de uma manifestação misógina no humor está entrelaçada com a possibilidade de causar um dano moral, entretanto, não se poderia estipular um critério objetivo para quais condutas se encaixam nesse artigo, uma vez que, a ofensa é, na maioria das vezes, uma questão subjetiva, uma piada pode ser considerada ofensiva para uns e não para outros, ademais, ao criar esse critério estaríamos discutindo a criação de um modelo de censura, o que não é vedado de acordo com a CF.

É importante citar que a $C F$, em seu artigo $5^{\circ}$, inciso $\mathrm{V}$, assegura o direito a resposta, o qual deve ser proporcional ao agravo, além de abordar a indenização por dano material, moral ou à imagem.

A liberdade de expressão é um direito garantido pela a Constituição, elemento que está no topo da hierarquia normativa do ordenamento jurídico brasileiro. Então, devíamos levá-la em consideração em detrimento do CP, Código Civil e de leis ordinárias, que estabelecem o crime de injúria, todavia, a própria Carta Magna estabelece como direitos fundamentais à honra, sendo a injúria caracterizado como o crime contra a honra. Ademais, outro direito fundamental por ela estabelecido é o direito ao trabalho, o comediante tem como sustento sua arte, as piadas que realizam, isso é o seu trabalho.

Estamos diante, portanto, de uma antinomia do direito brasileiro. Para solucionar antinomias entre os direitos fundamentais é necessário, caso elas - como nessa situação - não esteja estabelecido na Constituição, analisar a jurisprudência. Todavia, antes disso, é necessário discutir a relação entre o humor e a ofensa, visando entender melhor o modo como esses dois elementos se entrelaçam e se existe a obrigatoriedade da existência do humor na ofensa. 


\section{HUMOR VERSUS OFENSA}

É possível argumentar a necessidade do humorista de realizar piadas visando o seu sustento, mas é necessário que essas piadas ofendam alguém? Henry Bergson afirmaria que sim. De acordo com a visão desse estudioso realizar uma piada significa ferir alguém, entendendo que "para fazer-se humor, é preciso haver descaso para o outro, objeto da piada [...]. Para Bergson, não existe humor individual, ou humor entre duas pessoas, mas humor perante um grupo. Ri-se de alguém perante um grupo."30 Outros autores, ao abordar o tema, possuem uma visão semelhante a essa: Hobbes - em um pequeno trecho de sua obra o Leviatã - considera que uma pessoa rir do outro por causa de um defeito que possui, porque o outro encontra-se em um lugar considerado inferior ${ }^{31}$.

Celso Figueiredo Neto $^{32}$ enumera quatro teorias centrais que explanam a origem do humor. Uma dessas teorias é a da superioridade - a qual se alinha aos pensamentos mencionados anteriormente, considerando que as piadas resultam da relação de superioridade que um mantém sobre o outro na sociedade. Além disso ela tem como uma característica fundamental que a superioridade pode não ser aceita socialmente, mas no humor ela se torna socialmente aceitável.

Essa teoria tem suas raízes na Antiguidade Grega, na qual Aristóteles e Platão entendem que "o riso é uma expressão de escárnio dirigida aos menos afortunados" 33 . Baseando-se nessa teoria, Hendrick Wolff considera que um ponto de origem para as piadas seriam os grupos sociais que formam a sociedade, dando origem a piadas de nordestinos, homossexuais, pessoas do gênero feminino.

O humor se torna mais sutil e talvez mais ferino, porque trafega menor pelo dito e mais pelo não dito, ou ainda que dito, pela ambiguidade dos termos, seus duplo-sentidos, as variadas interpretações possíveis deixando a pessoa,

30 FIGUEIREDO NETO, C. Porque Rimos: Um Estudo do Funcionamento do Humor na Sociedade. Comunicação \& Sociedade. São Paulo, 2011, v. 33, n. 57 . Disponível em: <https://www.metodista.br/revistas/revistas-ims/idez.php/CSO/article/view/2833>. Acesso em: 25 set. 2019.

${ }^{31}$ HOBBES, T. Leviatã. In: FIGUEIREDO NETO, C. Porque Rimos: Um Estudo do Funcionamento do Humor na Sociedade. Comunicação \& Sociedade. São Paulo, 2011, v. 33, n. 57. Disponível em: $<$ https://www.metodista.br/revistas/revistas-ims/idez.php/CSO/article/view/2833>. Acesso em: 25 set. 2019.

${ }^{32}$ FIGUEIREDO NETO, op. cit., p. 3-10.

33 Ibid., p. 6. 
objeto da piada em situações a vezes, duplamente constrangedora, pois foi gozada e, em alguns casos, nem entendeu a piada...A questão de superioridade, nesses casos se expressa intelectual ou psiquicamente e diante da 'piada privada' da qual a pessoa objeto da piada não tem como se defender ou reagir, o agressor, o humorista, coloca-se na confortável situação de "atirar das trincheiras" pois ataca sem o risco de ser atacado ${ }^{34}$

Mas isso é apenas acerca de uma teoria, existindo mais três ${ }^{35}$, podendo dar a impressão que utilizando as origens abordadas pelas as outras três poderíamos considerar a existência de piadas que não ofendam. Todavia, Figueiredo Neto considera que nas manifestações de humor há a presença das quatro teorias, havendo a presença predominante de uma ou mais. Diante disso, toda piada ofenderia uma pessoa.

Fábio Porchat - humorista brasileiro - discorda desse ponto de vista, afirmando que atualmente não deve mais ser realizadas piadas que diminuam e ofendam as pessoas $^{3637}$. Ademais, a humorista brasileira Tatá Werneck, em uma entrevista a ISTOÉ ${ }^{38}$, ao ser questionada acerca de piadas que ofendem mulheres, afirmou que as piadas tem que executar apenas a sua função primária, isto é, fazer os outros rirem, não devendo ser utilizada para ofender indivíduos. Em outro momento, a humorista diz que o limite para o humor é o bom senso, um elemento subjetivo, que varia de indivíduo para indivíduo, não sendo possível a utilização dele como um requisito para mesurar quando ou não pode a piada ser realizada, pois o que a um ofende não necessariamente pode ser considerado ofensivo para o outro ${ }^{39}$. Vale destaca que

\footnotetext{
${ }^{34}$ Ibid., p. 7.

${ }^{35}$ As outras teorias mencionadas pelo autor são: teoria do alívio (humor serviria como um alívio entre dois indivíduos); teoria da incongruência que considera como origem do humor a quebra de expectativa; e a teoria cognitiva, a qual afirma que o humor surge a partir de uma linha de pensamento até ocorrer um salto paradoxal que ocasiona uma mudança de sentido.

${ }^{36}$ Vale destacar que na mesma entrevista Porchat afirmou que o "limite" para humor seria o bom senso, uma elemento, claramente, subjetivo

37 "Não dá mais para diminuir e humilhar pessoas", declara Fábio Porchat. Estadão, São Paulo, 12 abr. de 2019. Disponível em: https://www.emais.estadao.com.br/noticias/gente,nao-da-mais-para-diminuire-humilhar-as-pessoas-declara-fabio-porchart,7002789112.amp. Acesso em: 09 dez 2019.

${ }^{38}$ BRANDALISE, C. Tatá Werneck: "Não dá mais para usar piada para ofender". ISTOÉ, 13 abr. 2019. Disponível em: https://www.istoe.com.br/nao-da-para-usar-piada-para-ofender/. Acesso em: 09 dez. 2019.

39 Tatá Werneck: "o limite do humor é o bom senso". Guiame, 16 set. 2019. Disponível em: https://www.guiame.com.br/nova-geracao/geral/tata-werneck-o-limite-do-humor-e-o-bom-senso.html. Acesso em: 09 dez. 2019.
} 
Werneck, em momentos anteriores, já realizou piadas consideradas ofensivas, destacando uma piada que fez acerca de judeus e posteriormente, em seu pedido de desculpa, afirmou que sua intenção não era ofender, apenas realizar uma piada ${ }^{40}$, o que pode ser utilizado para demonstrar o caráter subjetivo que a ofensa possui, uma vez que, o que é considerado ofensivo para um indivíduo pode não ser para outro.

Diante do exposto, torna-se claro compreender que a visão acerca da ofensa no humor não possui um caráter unânime. Alguns estudiosos acreditam na possibilidade de o humor existir desvinculado da ofensa, enquanto outros consideram que eles estão fortemente entrelaçados. Do mesmo modo, há humoristas que afirmam que seria possível existir o humor sem ofensa, todavia, quando analisando o comportamento deles na prática, é possível perceber que já realizaram manifestações humorísticas que feriram a honra de alguém.

\section{JURISPRUDÊNCIA DO SUPREMO TRIBUNAL FEDERAL REFERENTES A TEMÁTICA}

Tendo como o foco jurisprudência do Supremo Tribunal Federal, não foi possível encontrar uma decisão que retrate o tema de uma maneira completa, apenas que com ele dialogam, sendo assim abordarei duas as quais considero que trazem mais elementos para a discussão: Habeas Corpus n. 82.424-1, Rio Grande do Sul e ADI (Ação Direita de Inconstitucionalidade) n. 4451

\subsection{HABEAS CORPUS N. 82.424-1, RIO GRANDE DO SUL}

Siegfried Ellwanger em suas obras prega a discriminação racial, induzindo o ódio aos judeus, incitando a sua inferiorizarão e segregação. Ellwanger foi absorvido

40 MENEGUELLI, G. Tatá Werneck se desculpa por piada com judeus: 'sou uma pessoa do bem'. Purepeople, Rio de Janeiro, 5 nov. 2013. Disponível em:https://www.purepeople.com.br/noticia/tatawerneck-se-descupla-por-piada-com-judeus-sou-uma-pessoa-de-bem_a12303/1. Acesso em: 09 dez. 2019. 
em primeira instância, mas condenado na segunda e recorreu através desse habeas corpus, defendendo a tese de que não constituía discriminação racial já que judeus não constitui uma raça. Apesar de ser debatido, principalmente, se judeus enquadramse no crime de racismo ou não, os ministro do STF - ao longo dos seus votos abordam quais seriam os limites da liberdade de expressão no Brasil.

O Ministro Maurício Correa, em seu voto, afirma que, diante de conflitos acerca de direitos, o que deve ocorrer é a prevalência dos direitos dos indivíduos que são atingidos pela publicação com o intuito da discriminação não ser esquecida pela população. Baseando-se nessa linha de pensamento, poderíamos considerar que as manifestações misóginas nos humor não são, portanto, consideras lícitas no ordenamento jurídico brasileiro. Todavia, é importante recordar que o voto é sobre um caso onde não há a presença do elementos humorístico, não possuí, desse modo, a intenção de fazer os outros rirem. Considerando isso, devemos lembrar da possibilidade do humorista não possuir o dolo, não abrangendo o crime de injúria do modo que ele é descrito no $\mathrm{CP}$.

Celso Mello possui uma visão semelhante a do voto anterior, considerando que a proteção da liberdade de expressão não permite as manifestações criminosas, não existindo no Brasil um direito ou garantia que possa ser considerado absoluto, ele afirma que "nenhum direito ou garantia pode ser exercido em detrimento da ordem pública ou com desrespeito aos direitos e garantias de terceiros". Ademais, de acordo com o Ministro, a igualdade e a dignidade humana constituem limites à liberdade de expressão, a qual não pode ser utilizada com propósitos criminosos. Ele entende:

[...] que a superação dos antagonismos existentes entre princípios constitucionais há de resultar da utilização, pelo Supremo Tribunal Federal, de critérios que Ihe permitem ponderar e avaliar, hinc et nunc, em função de determinado contexto e sobre uma perspectiva axiológica concreta, qual deve ser o direito a preponderar no caso, considerada a situação de conflito ocorrente, desde que, no entanto, a utilização do método da ponderação de bens e interesses não importe o esvaziamento do conteúdo essencial dos direitos fundamentais ${ }^{41}$.

${ }^{41}$ DE MELLO FILHO, J. C. In: BRASIL. Supremo Tribunal Federal. Habeas-corpus no 82.424-1 do Rio Grande do Sul. Ministro Moreira. Brasília, 17 out. 2003. p. 108. 
Gilmar Mendes ${ }^{42}$ comenta acerca do papel fundamental exercido pela liberdade de expressão e de imprensa na democracia, considerando que a utilização desses direitos para a discriminação racial prejudica a democracia, todavia, na sociedade plural em que vivemos, não se pode considerar esses princípios absolutos. Segundo Mendes, o que deve ocorrer é a utilização do princípio da proporcionalidade para decidir qual princípio preponderará. Ademais, Carlos Velloso considera que, apesar de ser um direito garantido pela CF, a liberdade de expressão não pode se sobrepor a dignidade da pessoa humana, outro direito garantido pela carta magna.

Já Carlos Ayres Brito ${ }^{43}$ considera que não há um crime nesse caso, apenas o uso da liberdade de expressão para demonstrar sua convicção política. De um modo análogo, poderíamos considerar que a utilização da liberdade de expressão para a realização de manifestações misóginas no humor tem apenas o intuito de contar uma simples piada? Se isso for feito, ocorreria a desconsideração do direito daqueles que se sentiram ofendidos pela manifestação.

O Ministro Sepúlveda Pertence ${ }^{44}$ destaca o perigo de considerar um livro como instrumento do crime "incitar", fazendo referência à ditadura militar - período, como citado anteriormente, marcado pena censura -, no qual indivíduos eram presos por causa de livros que possuíam. A censura constituí um dos aspectos que deve ser levado em consideração quando se fala em liberdade de expressão e os seus limites.

Por fim, Marco Aurélio Mello45, em seu voto, também traz a importância da liberdade de expressão para a constituição de uma democracia, mas afirma que os limites da liberdade de expressão se encontrariam presentes apenas em manifestações marcadas pela agressividade, que exponham o outro a uma situação de iminente perigo. Logo, de acordo com essa visão, nem tudo aquilo que é considerado ofensivo constituiria uma conduta ilícita.

\footnotetext{
42 MENDES, G. F. In: BRASIL. Supremo Tribunal Federal. Habeas-corpus no 82.424-1 do Rio Grande do Sul. Ministro Moreira. Brasília, 17 out. 2003.

${ }^{43}$ BRITTO, F. A. A. C. In: BRASIL. Supremo Tribunal Federal. Habeas-corpus no 82.424-1 do Rio Grande do Sul. Ministro Moreira. Brasília, 17 out. 2003.

${ }^{4}$ PERTENCE, J. P. S. In: BRASIL. Supremo Tribunal Federal. Habeas-corpus no ${ }^{82.424-1}$ do Rio Grande do Sul. Ministro Moreira. Brasília, 17 out. 2003.

${ }^{45}$ MELLO, M. A. M. F. In: BRASIL. Supremo Tribunal Federal. Habeas-corpus no 82.424-1 do Rio Grande do Sul. Ministro Moreira. Brasília, 17 out. 2003.
} 


\title{
4.2 AÇÃO DIRETA DE INCONSTITUCIONALIDADE N. 4451
}

O artigo 45, incisos II e III, da Lei Federal 9.504/1997, proibia, a partir do dia primeiro de julho do ano da eleição, o uso de:

\begin{abstract}
I - trucagem, montagem ou outro recurso de áudio ou vídeo que, de qualquer forma, degredem ou ridicularizem candidato, partido ou coligação, ou produzir ou veicular programa com esse efeito;

II - veicular propaganda política ou difundir, opinião favorável ou contrária a candidato, partido, coligação, a seus órgãos ou representantes ${ }^{46}$.
\end{abstract}

Trucagem é - segundo essa legislação (artigo $45, \S 4^{\circ}$ ) - "todo e qualquer efeito realizado em áudio ou vídeo que degradar ou ridicularizam candidato, partido político ou coligação, ou que desvirtuar a realidade e beneficiar ou prejudicar qualquer candidato, partido político ou coligação"47.

Diante disso, a Associação Brasileira de Emissoras de Rádio e Televisão (ABERT) entrou como uma ação pleiteando a inconstitucionalidade de tais incisos com base no direito à liberdade de expressão. Tal ação relaciona-se, claramente, com o tema, pois trata-se em parte do uso do humor que pode ser considerado ofensivo e sua relação com a liberdade de expressão.

Foi deferido, unanimemente, a inconstitucionalidade de tais incisos, mas após seu término foram intimadas autoridades para darem pareceres na questão. $O$ Presidente do Senado Federal, a Presidente da República, o Advogado-Geral da União e o Procurador da República possuem pontos de vistas divergentes da decisão, defendendo a constitucionalidade da norma em questão, visando garantir uma processo eleitoral justo. O Presidente da Câmara de Deputados considerou que a matéria foi julgada pelo STF dentro dos trâmites constitucionais e regimentais.

O relator do caso, o Ministro Alexandre de Moraes, defende a inconstitucionalidade dos incisos II e III, tendo como fundamento da liberdade de expressão garantida no artigo $5^{\circ}$ da CF. Além disso, ao longo de seu voto, ele usa

${ }^{46}$ BRASIL. Lei no 9.504, de 30 de setembro de 1997. Estabelece normas para a eleição. Diário Oficial [da] República Federativa do Brasil, Brasília, DF, 30 set. 1997. Disponível em: www.planalto.gov.br/ccivil_03/LEIS/L9504.htm. Acesso em: 9 dez. 2019. 47 Ibid. 
como justificativa decisões e pontos de vistas oriundos do Estados Unidos, país que - como já foi mencionado anteriormente - possui uma relação diferente com a liberdade de expressão que aquela que predomina no Brasil, entendendo a liberdade de expressão, na grande maioria dos casos (e naqueles trazidos pelo ministro) como um direito absoluto. ${ }^{48}$

Ademais, vale destacar que, outro ponto por ele apresentado foi o voto da Ministra Carmen Lúcia na ADI n. 815, acerca das censura prévia - a qual era prevista nos artigos 20 e 21 do Código Civil ${ }^{49}$-, ou seja, a exigência legal de autorização para a divulgação ou publicação de biografias por aquele que teve sua história contada na obra. A Ministra considerou esses artigos inconstitucionais, referindo-se a proibição clara da Constituição à censura. Moraes faz uma analogia entre esse voto e o caso em questão.

Barroso complementa o voto de Morais, considerando que levando em consideração o princípio de unidade da constituição não poderá existir uma hierarquia de direitos fundamentais, sendo assim, hierarquizar esses direitos seria inconstitucional. Ademais, ele afirma que, de acordo com o seu ponto de vista, no STF é majoritário o caráter preferencial da liberdade de expressão, isto é, "embora não exista hierarquia entre as normas constitucionais, a liberdade de expressão desfruta de uma primazia prima facie, ou seja, em princípio ela deve prevalecer"50. Além disso o referido ministro faz referência a censura que marcou o Brasil durante a ditadura militar com o intuito de destacar a importância da liberdade de expressão.

Rosa Weber traz um elemento novo para a discussão, ela remete a discussões acerca da ineficácia do direito de respostas em charges ou programas humorísticos, entretanto, entende que o eleitor verá essas manifestações como uma opinião artística

\footnotetext{
48 MORAIS, A. In: BRASIL. Supremo Tribunal Federal. Ação Direita de Inconstitucionalidade ㄲo 4451 . Ministro Alexandre de Moraes. Brasília, 20 jul. 2018.

${ }^{49}$ Artigo 20. Salvo se autorizadas, ou se necessárias à administração da justiça ou manutenção da ordem pública, a divulgação de escritos, a transmissão da palavra, ou a publicação, a exposição ou a utilização da imagem de uma pessoa poderão ser proibidas a seu requerimento e sem prejuízo da indenização que couber, se lhe atingirem a hora, a boa fama ou a responsabilidade ou se se destinarem a fins comerciais. Parágrafo único - Em se tratando de morto ou de ausente, são partes legítimas para requerer essa proteção o cônjuge, os ascendentes ou os descentes. Artigo 21. A vida privada da pessoa natural é inviolável, e o juiz, a requerimento do interessado, adotará as providências necessárias para impedir ou fazer cessar ato contrário a esta norma. In: BRASIL. Lei 10.406, 10 de janeiro de 2012. Código Civil. Diário Oficial da União, Brasília, 11 jan. 2012.

50 BARROSO, L. R. In: BRASIL. Supremo Tribunal Federal. Ação Direita de Inconstitucionalidade no 4451. Ministro Alexandre de Moraes. Brasília, 20 jul. 2018. p. 39.
} 
e/ou humorística, não devendo os direitos previstos na CF serem cessados para se manter o equilíbrio eleitoral..$^{51}$

Gilmar Mendes - em seu voto - aborda os limites a liberdade de expressão, afirmando que não se trata de um direito absoluto, mas tais limites devem ser impostos a partir da observância das normas presentes na CF. O ministro também traz o direito comparativo em seu voto, fazendo referência ao direito alemão, mais especificamente decisões acerca da relação entre a liberdade artísticas (o que incluí a liberdade para a realização de manifestações misóginas) e os outros direitos garantido ao cidadão, além de referências ao direito estadunidense. Além disso, ele discute sobre decisões do próprio STF que corroboram o seu ponto de vista, o que demonstra que até nesse órgão da justiça brasileira não se há uma unanimidade acerca de elementos que dialoguem com a questão abordada pelo artigo, uma vez que, mesmo sendo sério ou humorístico, os dois tipos de manifestações podem ofender o outro. ${ }^{52}$

Diante da análise dos votos de dois julgamentos do STF analisados, é possível perceber que não há um consenso no judiciário brasileiro. Enquanto no primeiro mesmo não abordando diretamente o assunto - prevalece o entendimento que há sim limites para a liberdade de expressão, o segundo vai argumentar na primazia desse direito nas manifestações humorísticas na política, mesmo que elas firam a honra do candidato.

\section{CONCLUSÃO}

O status das manifestações misóginas no humor no ordenamento jurídico brasileiro é um assunto complexo, envolvendo vertentes distintas, as quais devem ser analisadas com atenção e cuidado. São diferentes pontos de vista que devem ser

\footnotetext{
51 WEBER, R. M. P. In: BRASIL. Supremo Tribunal Federal. Ação Direita de Inconstitucionalidade no 4451. Ministro Alexandre de Moraes. Brasília, 20 jul. 2018.

52 MENDES, G. F. In: BRASIL. Supremo Tribunal Federal. Ação Direita de Inconstitucionalidade no 4451. Ministro Alexandre de Moraes. Brasília, 20 jul. 2018.
} 
levados em consideração e diferentes abordagens que podem ser utilizadas para alcançar o objetivo.

A liberdade de expressão é um direito garantido pela CF, todavia, apesar de uma parcela da população acreditar ser este direito amplo, há limites acerca dele. $\mathrm{O}$ indivíduo ao praticar um ato pode ultrapassar os direitos fundamentais de outrem, o que pode ser caracterizado como uma injúria, delimitando, assim, sua liberdade de expressão.

Sendo o dolo um dos elementos imprescindível para classificar um ato como injúria, permanece a indagação: há em manifestações misóginas o dolo, classificandoo assim como uma injúria, se a intenção do humorista ao contar uma piada é fazer o outro rir?

Partindo do pressuposto de que a honra, por possuir um conceito subjetivo, variando de acordo com os costumes e a cultura do grupo social em que o indivíduo está inserido, o legislador ao imputar ao humorista uma pena alicerçada no ferimento da honra de alguém, pode incidir na censura, a qual fere os preceitos da CF.

Ao analisar a jurisprudência brasileira, na tentativa de responder o questionamento, encontrei duas decisões que abordam a temática ou possui um foco paralelo a ela, que merecem destaque. A primeira corrobora com o pensamento de que a liberdade de expressão é um direito limitado no Brasil; alguns Ministros, nesta decisão, evidenciaram que o limite são os atos que ferem a honra de outrem, considerando estas ações criminosas. Já a outra decisão preceituou inconstitucional o tipo penal que afirma ser crime manifestações humorísticas que ridicularizam ou degradam determinado político em período próximo à eleição, usando como principal argumento a liberdade de expressão. Sendo assim, tendo como bases estas decisões, é possível considerar um dos limites da liberdade de expressão ações criminosas, porém manifestações humorísticas misóginas não se enquadram no perfil acima, sendo, portanto, considerada legal. Todavia, a esse pensamento ainda há um empecilho: a honra.

Assim sendo, não foi possível encontrar uma resposta clara e objetiva na legislação brasileira a respeito do questionamento feito neste projeto, o mesmo pode se dizer acerca da jurisprudência. Diante disso, cheguei a uma única conclusão: não 
se é possível, levando em consideração as interpretações e recursos que entrei em contato ao longo da pesquisa, encontrar uma resposta objetiva para a pergunta em questão.

A liberdade de manifestação - tanto de pensamento quanto a artística constitui um dos pilares da sociedade democrática em que vivemos, mas os direitos daqueles que se sentiram ofendidos pelas manifestações não podem ser desconsiderados. Sendo assim, posso afirmar que cada caso deve ser analisado individualmente, levando em consideração seu contexto, suas peculiaridades e o princípio da proporcionalidade, não sendo possível, portanto, ter uma certeza absoluta sobre o assunto. Sobre um aspecto, todavia, é possível ter certeza - se a questão for analisada sob o ponto de vista de Sartre, não haveria um debate acerca dos status das manifestações misóginas no humor, pois seria possível afirmar que no Brasil não há liberdade.

\section{REFERÊNCIAS}

AMORIM, R. G. Immanuel Kant: "O maior filósofo dos tempos modernos". In: Coleção Estudo Filosofia/ Sociologia. Belo Horizonte: Bernoulli Sistemas de Ensino, 2017, v. 2.

AMORIM, R. G. Os principais pensadores do século XX. In: Coleção Estudo Filosofia/ Sociologia. Belo Horizonte: Bernoulli Sistemas de Ensino, 2017, v. 2.

BRANDALISE, C. Tatá Werneck: "Não dá mais para usar piada para ofender". ISTOÉ, 13 abr. 2019. Disponível em: https://www.istoe.com.br/nao-da-para-usarpiada-para-ofender/. Acesso em: 09 dez. 2019.

BRASIL. Supremo Tribunal Federal. Ação Direita de Inconstitucionalidade no 4451. Ministro Alexandre de Moraes. Brasília, 20 jul. 2018.

BRASIL. Agravo Regimental em Mandado de Segurança 34.493 Bahia, de 06 de Maio de 2019. Brasília, 3 maio 2019.

BRASIL. Constituição da República Federativa do Brasil. Brasília, DF: Senado, 1988.

BRASIL. Decreto-Lei 2.848, de 07 de dezembro de 1940. Código Penal. Diário Oficial União, Rio de Janeiro, 31 dez 2019.

BRASIL. Lei 10.406, 10 de janeiro de 2012. Código Civil. Diário Oficial da União, Brasília, 11 jan. 2012. 
BRASIL. Lei 11.340, de 7 de agosto de 2006. Diário Oficial [da] República Federativa do Brasil, Brasília, DF, 7 ago. 2006. Disponível em: www.planalto.gov.br/ccivil_03/_ato2004-2006/2006/lei/111340.htm. Acesso em: 15 nov. 2019.

BRASIL. Lei no 9.504, de 30 de setembro de 1997. Estabelece normas para a eleição. Diário Oficial [da] República Federativa do Brasil, Brasília, DF, 30 set. 1997. Disponível em: www.planalto.gov.br/ccivil_03/LEIS/L9504.htm. Acesso em: 9 dez. 2019.

BRASIL. Supremo Tribunal Federal. Habeas-corpus no 82.424-1 do Rio Grande do Sul. Ministro Moreira. Brasília, 17 out. 2003.

CAZELATTO; Caio Eduardo Costa; CARDIN, Valéria Silva Galdino. Minorias Sexuais e Discurso de Ódio. Rio de Janeiro: Lumen Juris, 2018.

DIMOULIS, D.; MARTINS, L. Teoria Geral dos Direitos Fundamentais. 5. ed. São Paulo: Atlas, 2014.

FIGUEIREDO NETO, C. Porque Rimos: Um Estudo do Funcionamento do Humor na Sociedade. Comunicação \& Sociedade. São Paulo, v. 33, n. 57, 2011. Disponível em: https://www.metodista.br/revistas/revistas-ims/idez.php/CSO/article/view/2833. Acesso em: 25 set. 2019.

HOBBES, T. Leviatã. In: FIGUEIREDO NETO, C. Porque Rimos: Um Estudo do Funcionamento do Humor na Sociedade. Comunicação \& Sociedade. São Paulo, v. 33, n. 57, 2011. Disponível em: https://www.metodista.br/revistas/revistasims/idez.php/CSO/article/view/2833. Acesso em: 25 set. 2019.

HUNGRIA, N. Comentários ao Código Penal. In: LENZA, P. (Org.). Direito Penal Esquematizado: Parte Especial. 8. ed. São Paulo: Saraiva, 2018.

LENZA, P. (Org.). Direito Penal Esquematizado: Parte Especial. 8. ed. São Paulo: Saraiva, 2018.

LIBERDADE. In: Dicionário Aurélio da Língua Portuguesa. Brasil: Positivo, 2019.

Limites Ultrapassados: Danilo Gentili é condenado à prisão por injúria contra deputada Maria do Rosário. Consultor Jurídico, 11 abr. 2019. Disponível em: https://www.conjur.com.br/29-abr-11/danilo-gentili-condenado-prisao-injuria-mariarosario. Acesso em: 30 abr. 2019.

MENDONÇA, B. M. Liberdade: dos Pensadores ao Direito Fundamental. Direito UNIFACS - Debate Virtual, Salvador, v. 227, maio 2019. Disponível em:

https://www.revistas.unifacs.br/index.php/redu/article/view/513. Acesso em: 12 dez. 2019.

MENEGUELLI, G. Tatá Werneck se desculpa por piada com judeus: 'sou uma pessoa do bem'. Purepeople, Rio de Janeiro, 5 nov. 2013. Disponível em:<https://www.purepeople.com.br/noticia/tata-werneck-se-descupla-por-piadacom-judeus-sou-uma-pessoa-de-bem_a12303/1>. Acesso em: 09 dez. 2019.

MOREIRA, A. Racismo Recreativo. São Paulo: Polén, 2019

$\mathrm{RUCH}$, W. The Perception of Humor. In: KASZNIAK, A. W. Emotions, Qualia, and Consciousness. Düsseldorf: World Scientific Publishing Co. Pet. Ltd., 2001. 
SÃO PAULO. 5 $5^{\mathrm{a}}$ Vara Criminal do Tribunal Federal da 3ª Região. Ação Penal Privada. São Paulo, 10 abr. 2019.

SARMENTO, D. A Liberdade de expressão e o problema do "hate speech". Livres e iguais: estudo de direito constitucional, Rio de Janeiro: Lumen Juris, 2006.

Disponível em: http://www.dsarmento.adv.br/content/3-publicacoes/18-a-liberdadede-expressao-e-o-problema-do-hate-speech/a-liberdade-de-expressao-e-oproblema-do-hate-speech-daniel-sarmento.pdf. Acesso em: 28 maio 2019.

TARDELLI, E. Adilson Moreira: "O humor racista é um tipo de discurso de ódio". Carta Capital, 18 dez. 2018. Disponível em:

https://www.cartacapital.com.br/justica/adilson-moreira-o-humor-racista-e-um-tipode-discurso-de-odio/. Acesso em: 12 dez. 2019.

VAN DAMME, E. Gender and sexual scripts in popular US teen series: A study on the gendered discourses in One Tree Hill and Gossip. Catalan Journal of

Communication \& Cultural Studies. Gante, Bélgica: Intellect Ltd Article, v. 2, n. 1, 2010.

VILLA, M. A. História das Constituições Brasileiras. São Paulo: Textos Editores LTDA., 2011. 